\title{
EVALUATION OF THE EFFECTS OF ILLUMINATION, TEMPERATURE AND PAINTING FINISH IN PSP TECHNIQUE
} \author{
and J. B. P. Falcao Filhob \\ Rodovia Presidente Dutra, km 134, CEP: \\ 12247-820, Distrito - Rod. Pres. Dutra, \\ km 137, Eugênio de Melo, \\ São José dos Campos, SP, Brazil \\ rafael.costa@embraer.com.br \\ bInstituto de Aeronáutica e Espaço \\ Praça Mal. Eduardo Gomes, 50 \\ São José dos Campos,SP, Brasi \\ Received: November 18, 2013 \\ Revised: November 21, 2013 \\ Accepted: December 30, 2013

$\begin{array}{ll}\text { A, B } & \text { Stern-Volmer coefficients } \\ \text { I } & \text { luminescence intensity } \\ \text { P } & \text { air pressure, } \mathrm{Pa} \\ \mathrm{q} & \text { dynamic pressure, } \mathrm{Pa} \\ \mathrm{T} & \text { Temperature, } \mathrm{C} \\ \mathrm{t} & \text { time, } \mathrm{S}\end{array}$

R. S. Costa ${ }^{a}$,

A. C. Avelar ${ }^{\text {, }}$

${ }^{\mathrm{a}}$ Embraer Vila das Acacias,

\section{ABSTRACT}

This paper reports the results of global pressure measurements on a NACA0012 profile, obtained with the Pressure Sensitive Paint technique (PSP), and compares them with conventional pressure tap measurements with the purpose of analyzing the influence of parameters as illumination efficiency and temperature variation of the air flow in the accuracy of the PSP experimental results. The experimental measurements were conducted in the Pilot Transonic Wind Tunnel (TTP) of the Instituto de Aeronáutica e Espaço (IAE) for Mach number values of 0.4, 0.6 and 0.8. The experiments showed that in a carefully prepared experiment, under appropriated operational conditions, and rigorous adjustments of the PSP components, the obtained results can be accurate. Moreover, even when the influence of temperature is significant and the illumination condition is not ideal, it was possible to estimate well the impact caused in the pressure distribution over the model surface.

Keywords: Pressure Sensitive Paint (PSP), Pressure taps, Transonic Wind Tunnel, NACA0012 profile

\section{NOMENCLATURE}

\section{Subscripts}

$\begin{array}{ll}\text { ref } & \text { at a reference condition } \\ \text { o } & \text { total } \\ \text { st } & \text { static }\end{array}$

\section{INTRODUCTION}

Wind tunnel tests for study of flow characteristics and the analysis of their effects on aircrafts, rockets or any specific part of them are essential in the development of an aerospace project. One very important task is to acquire the surface pressure distribution on a model for structural analysis and for optimizing global aerodynamics coefficients. In general, pressure information is obtained through pressure taps measurements, which consists of installing arrays of small orifices on a model surface and connecting them throught small flexible tubes to pressure transducers. This technique, relatively simple, provides good results, but has also some drawbacks. It is costly in price and in time to manufacture and to prepare a model with the hundreds of pressure taps necessary to provide a reasonable resolution. In addition it is not possible to install pressure taps in very thin areas of the model. A relatively new alternative for pressure measurements in aerodynamic testing, that provides a solution for measurements in thin areas is the technique of Pressure Sensitive Paint (PSP) that has been used recently in several wind tunnel around the world as a standard technique for obtaining quantitative global pressure measurement on model surfaces (Vardaki, et al. 2012). The method provides, in a non-intrusive way and with high spatial resolution, quantitative pressure values on a model surface (Engler et al., 2000). The main advantages of the PSP technique are the high resolution, which allows a complete pressure mapping of the entire surface of the model (Basu et al., 2009) and the possibility of obtaining data pressure at locations where it would be impossible with conventional methods (Kurita et al., 2006). The PSP technique is very feasible for predicting aerodynamic loads and validating computational fluid dynamics (CFD) data. Detailed information about the PSP method and its historical development can be obtained in Liu and Sulivan (2005), in Gregory et al. (2007) and in Bell et al. (2001). 
The experiments described in this paper were carried out in the Pilot Transonic Wind Tunnel (TTP) of the Instituto de Aeronáutica e Espaço (IAE), with the aim of investigating the effects of illumination and temperature variation on results obtained with the PSP technique, which was recently implemented in TTP. The measurements were conducted for Mach number of $0.4,0.6$ and 0.8 . It was verified that in a carefully planned PSP experiment, the accuracy of this technique can be very satisfactory. Moreover, the pressure distribution on a model surface can be satisfactorily predicted even in experiments with some temperature variations.

\section{PSP WORKING PRINCIPLE}

The PSP technique requires a special paint in which the luminescence is inversely dependent to air local pressure. This paint is applied upon the surface of a wind tunnel model and the pressure distribution is obtained from images produced by proper illumination. The PSP technique is based on an oxygen-quenching process in which excited molecules are deactivated with oxygen. This phenomenon produces different degrees of luminosity on the model surface. The final pressure map is obtained using complex image processing techniques (Engler et al., 2000).

As it is shown in Fig. 1, generally pressure sensitive paint is composed of two main parts, an oxygen permeable binder, and an oxygen-sensitive molecule, luminophore. When a luminescent molecule absorbs energy through a specific light, the molecule raises to energy excited state. Then, in most of times the molecules recover to the ground state by the emission of a photon of a longer wave length.

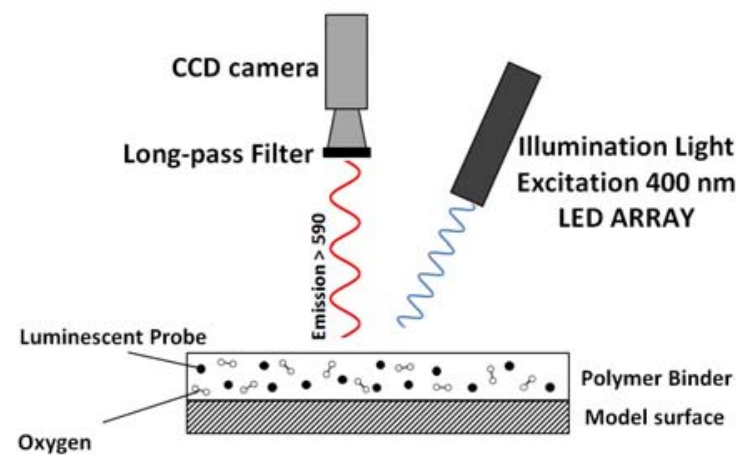

Figure 1. Schematic representation of PSP work principle.

The intensity of the luminescence gives a measure of the partial pressure of oxygen and hence the local air pressure. If the paint receives a pulse of light, the luminescence will decay exponentially to the ground state, characterizing the Lifetime method and that is also quenched by oxygen. Unfortunately, the luminescent intensity distribution does not depend only on the partial pressure of oxygen. In fact it varies with illumination intensity, paint layer thickness and uniformity, and the surface temperature. These variations can cause a non-uniform signal from the painted surface and can be eliminated or minimized taking the ratio of the luminescence intensity, wind-on and wind-off, ratio, where wind-off means wind tunnel turned off, and wind-on, wind tunnel turned on.

$$
\frac{I_{r e f}}{I}=A+B \frac{p}{p_{r e f}}
$$

With this procedure, the response of the system can be modeled using a modification of the Stern-Volmer equation, Eq. (1), (Liu and Sullivan, 2005), where, I, is the luminescence at an unknown test condition (wind-on) and $I_{\text {ref }}$, is the luminescence at a reference test condition at the wind tunnel test section (windoff).

Lifetime based PSP measurement includes phasesensitive detection and multi-gate integration techniques. A schematic representation of these gates is shown in Fig. 2. In the first phase, the paint receives a short illumination pulse and its molecules are excited to the maximum point of energy, so after, the luminescence is emitted and decay exponentially to the ground state, characterizing the second phase. The Lifetime method is obtained through the integration of the gate one $\left(t_{1}-t_{2}\right)$, and gate two $\left(t_{3}-\right.$ $t_{4}$ ) ratio. The signal from the first phase is sensitive to the intensity from the illumination pulse and relatively insensitive to pressure and the second phase is also sensitive to the intensity from the illumination pulse, but very sensitive to pressure. Then, by taking the ratio of the two gates it is possible to remove the signal of illumination, resulting in a signal of pressure.



Figure 2. Schematic representation of Life-time method working principle (modified from Vardaki et al., 2010).

Typically the PSP system consists of illumination devices, CCD cameras or photomultiplier, a filter, that separates the illumination from the red shifted 
emission of the luminescent molecules, data acquisition and reduction systems, PSP paint, and in the case of Lifetime method, a synchronism device between camera, illumination system and the PC, as represented in Fig. 3. The luminescent intensity distribution is recorded and stored for conversion to pressure using a calibration, which can be performed a priori or in situ.

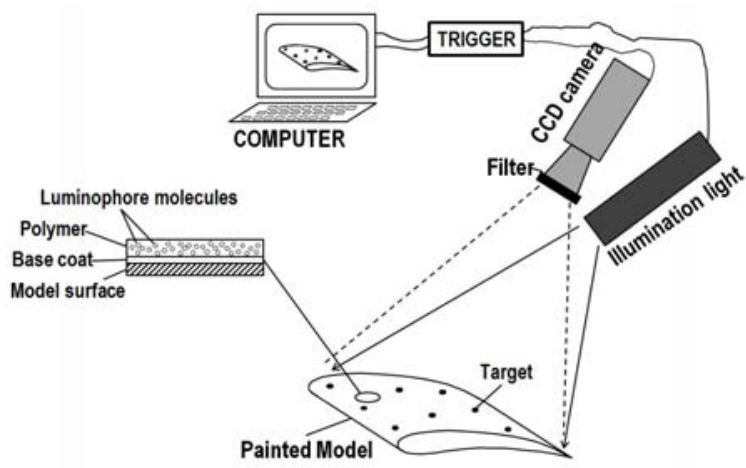

Figure 3. Schematic representation of a pressuresensitive paint measurement system.

\section{DESCRIPTION OF THE EXPERIMENT}

The pressure measurements were conducted in TTP wind tunnel, which is a modern installation, with a conventional closed circuit, continuously driven by a main compressor of $830 \mathrm{~kW}$ of power, and with an intermittent injection system which operates in a combined mode, for at least 30 seconds. Its test section is $30 \mathrm{~cm}$ wide and $25 \mathrm{~cm}$ high, with slotted walls. The tunnel has automatic controls of pressure (from 0.5 bar to 1.25 bar), Mach number (from 0.2 to 1.3), temperature and humidity, related to test section (Falcão Filho et al., 2009). Figure 4 shows a partial view of the TTP's aerodynamic circuit.

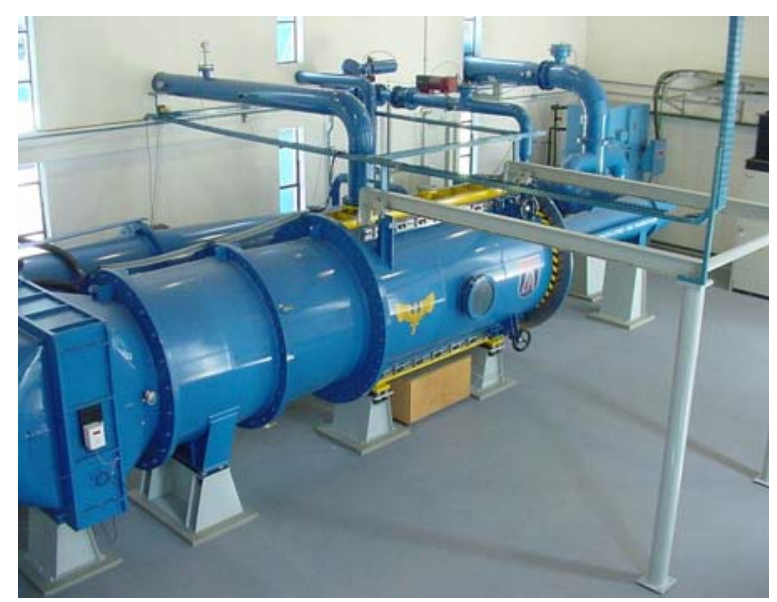

Figure 4. TTP Wind Tunnel.

A commercial UniFIB paint, purchased from Innovative Scientific Solutions, Inc. (ISSI) has been used. Before being fixed in the wind tunnel test section the model was carefully cleaned with acetone and painted with the PSP paint, which was applied with an airbrush. A tiny layer of FIB basecoat (ISSI FB-200) was sprayed on the NACA0012 surface followed by the application of the top coat (ISSI UF400). In order to avoid blockage of the pressure taps, air was gently blew through the holes during the painting procedure. Once painted, the model was dried up in an oven at $60{ }^{\circ} \mathrm{C}$ for $90 \mathrm{~min}$. Finally it was installed in the wind tunnel test section, as shown in Fig. 5.

The NACA 0012 airfoil is symmetric with $12 \%$ of thickness in relation to the aerodynamic chord. It was made of aeronautic Aluminum with chord of 83 $\mathrm{mm}$ and with $250 \mathrm{~mm}$ of span, representing a blockage ratio of $3.32 \%$ related to test section dimensions. Five pressure taps were drilled locally perpendicularly to the surface with $0.5 \mathrm{~mm}$ of diameter and located from the leading edge at $6.0 \%$, $25.3 \%, 39.8 \%, 56.3 \%$ and $70.5 \%$ of the chord direction. For visualization purpose, the profile was installed vertically in the test section (Fig. 5) by means of cylindrical shaft passing through $8 \mathrm{~mm}$ holes in the upper and lower walls. External fixing device were used to clamp the shaft holding in position and also allowing adjustment of the angle of attack.

For the PSP measurements the model was illuminated using a 400nm frequency LED (Light mission Diode) LM2X-DM-400. The images were acquired by using a PCO 160014 bit cooled CCD camera with $1600 \times 1200$ pixels of resolution fitted with a Nikkon lens f\# 2.8 with focal length of 55mm.

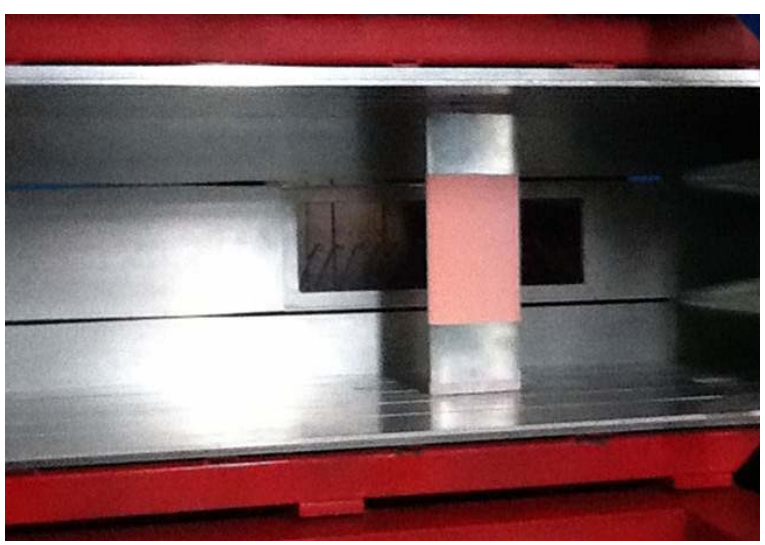

Figure 5. NACA0012 profile in the wind tunnel test section.

A Quantum Composer 9600+ pulsed generator was used for the synchronism between the camera, illumination system and the computer, and a commercial system from ISSI was used for data acquisition and analysis.

In the present work, the influence of the following parameters was investigated: Mach number (values of 0.4, 0.6 and 0.8, with zero angle of attack), camera aperture, temperature and illumination, and 
preliminary results will be presented. A more detailed investigation has still to be accomplished in order to enhance reliability of this technique in the TTP wind tunnel.

\section{RESULTS AND DISCUSSIONS}

Table 1 to Tab. 3 show the conditions investigated in each of the three tests that were carried out. In test A the Mach number was varied, in test B the temperature in which the experiments were conducted was varied. Finally in test $\mathrm{C}$ the camera aperture was changed. All tests were carried out for zero angle of attack.

Table 1. Test A - Mach number variation.

\begin{tabular}{|c|c|c|c|}
\hline & \multicolumn{3}{|c|}{ Test A } \\
\hline Mach Number & 0.4 & 0.6 & 0.8 \\
\hline$p_{\text {amb }}(\mathrm{Pa})$ & 93110 & 93100 & 93080 \\
\hline$p_{0}(\mathrm{~Pa})$ & 93990 & 93998 & 94007 \\
\hline$p_{\text {st }}(\mathrm{Pa})$ & 84150 & 73701 & 61720 \\
\hline$q(\mathrm{~Pa})$ & 9425 & 18573 & 27651 \\
\hline$T_{\text {st }}\left({ }^{\circ} \mathrm{C}\right)$ & 28.3 & 27.8 & 27.4 \\
\hline$T_{0}\left({ }^{\circ} \mathrm{C}\right)$ & 32.0 & 33.4 & 35.7 \\
\hline $\begin{array}{c}\text { Camera } \\
\text { aperture }\end{array}$ & 2.8 & 2.8 & 2.8 \\
\hline Focus & 0.64 & 0.64 & 0.64 \\
\hline
\end{tabular}

Table 2. Test B - variation in the temperature in which the experiments were conducted.

\begin{tabular}{|c|c|c|}
\hline \multirow{2}{*}{ Test B } & \multicolumn{2}{|c|}{ Mach Number } \\
\cline { 2 - 3 } & 0.6 & 0.6 \\
\hline$p_{\text {amb }}(\mathrm{Pa})$ & 93080 & 93060 \\
\hline$p_{\mathrm{o}}(\mathrm{Pa})$ & 94034 & 94014 \\
\hline$p_{\mathrm{st}}(\mathrm{Pa})$ & 73733 & 73729 \\
\hline$q(\mathrm{~Pa})$ & 18581 & 18580 \\
\hline$T_{\text {st }}\left({ }^{\circ} \mathrm{C}\right)$ & 27.0 & 38 \\
\hline$T_{\mathrm{o}}\left({ }^{\circ} \mathrm{C}\right)$ & 33.1 & 42.2 \\
\hline Camera aperture & 5.6 & 5.6 \\
\hline Focus & 0.64 & 0.64 \\
\hline
\end{tabular}

Table 3. Test $\mathrm{C}$ - camera aperture variation.

\begin{tabular}{|c|c|c|}
\hline \multirow{2}{*}{ Test B } & \multicolumn{2}{|c|}{ Mach Number } \\
\cline { 2 - 3 } & 0.6 & 0.6 \\
\hline$p_{\text {amb }}(\mathrm{Pa})$ & 93050 & 93080 \\
\hline$p_{\mathrm{o}}(\mathrm{Pa})$ & 93993 & 94019 \\
\hline$p_{\text {st }}(\mathrm{Pa})$ & 73660 & 73657 \\
\hline$q(\mathrm{~Pa})$ & 18562 & 18562 \\
\hline$T_{\text {st }}\left({ }^{\circ} \mathrm{C}\right)$ & 28.0 & 27.0 \\
\hline$T_{\mathrm{o}}\left({ }^{\circ} \mathrm{C}\right)$ & 34.1 & 33.1 \\
\hline Camera aperture & 11 & 2.8 \\
\hline Focus & 0.64 & 0.64 \\
\hline
\end{tabular}

Figure 6 to Fig. 11 show PSP results obtained for Mach number values of $0.4,0.6$ and 0.8 , with the same camera aperture and with as small as possible changes in the stagnation temperature. The ProImage software, used for PSP image processing, provides pressure profiles along any line traced over the PSP pressure field image, as shown in small graphics displayed in Figs. 6, 8 and 10. These results show the capacity of this technique in which it is possible to obtain the pressure distribution over any direction desirable. In Figs. 7, 9 and 11 comparisons of both techniques in the experiment, PSP and pressure taps, are shown.

For Mach number 0.4, data from literature in terms of $c_{p}$ (Harris, 1981) can be used to obtain the lowest pressure value over the profile for the same stagnation pressure (about $94000 \mathrm{~Pa}$ ) which is equal to $80000 \mathrm{~Pa}$. This value agrees more with the pressure taps results while PSP results were about 1000 Pa lower (see Fig. 7). For Mach number 0.6 the value from the literature resulted in a lowest pressure of about $64000 \mathrm{~Pa}$. In this case, the pressure taps value was about $1000 \mathrm{~Pa}$ higher and the PSP value was about 1000 Pa lower (see Fig. 9).



Figure 6. PSP results for Mach number $=0.4$.

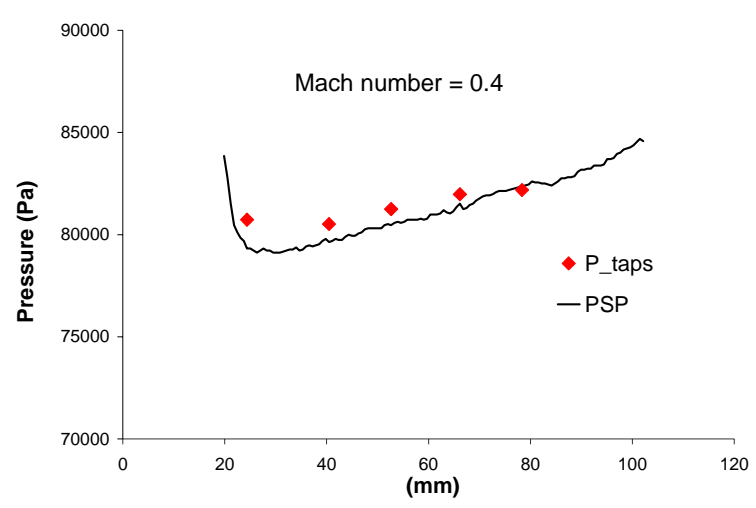

Figure 7. Pressure tap and PSP results for Mach number $=0.4$.

For Mach number 0.8 it is more difficult to make comparisons because in this case the shape of the curve diverged from the literature, due to the shock and laminar boundary layer interaction. It is important to say that the profile chord used in the 
experiments in TTP was $83 \mathrm{~mm}$, very small compared with the profiles commonly tested in industrial wind tunnels. Consequently the data from the literature normally represent results for the turbulent region where the boundary layer is not so affected by the impinging shocks because of its much greater inertia (Van Dyke, 1988).



Figure 8. PSP surface pressure field for Mach $=0.6$.

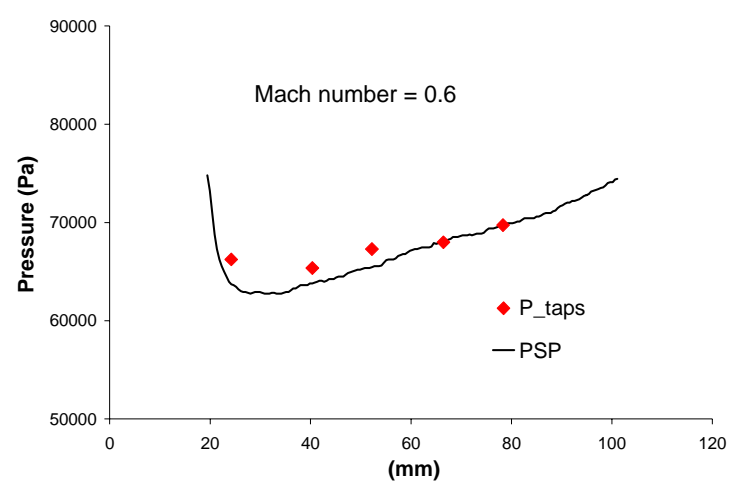

Figure 9. Pressure taps and PSP results for Mach number $=0.6$.

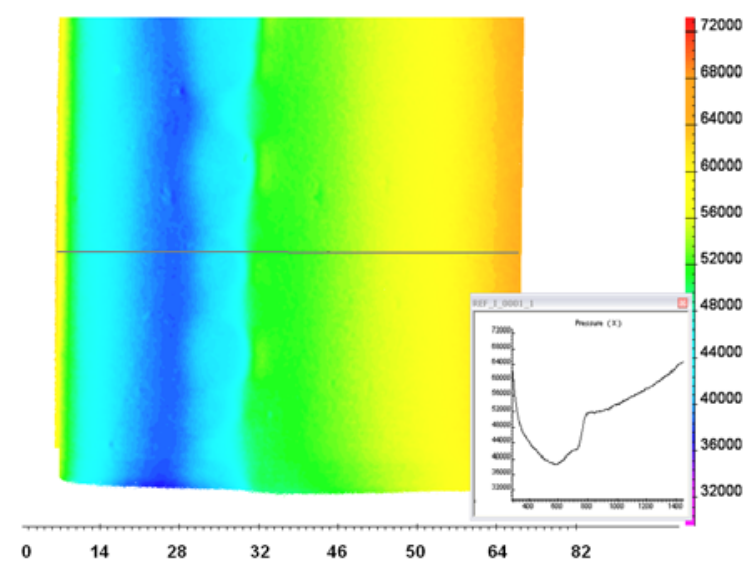

Figure 10. PSP surface pressure field for Mach for Mach $=0.8$.

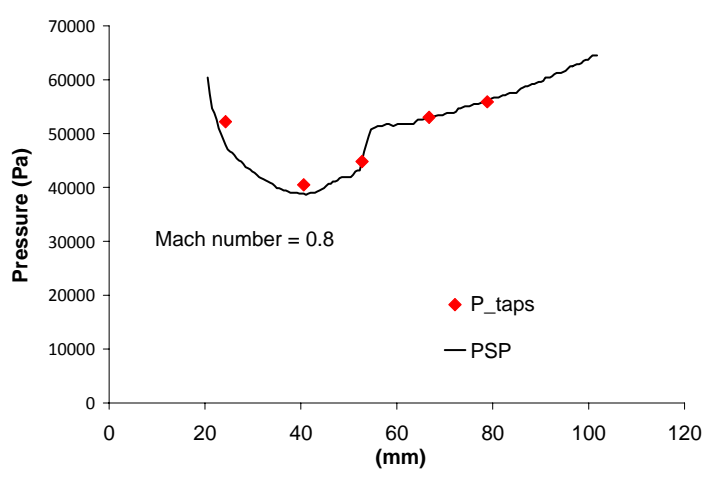

Figure 11. Pressure taps and PSP results for Mach number $=0.8$.

However, particularly in this case, both experimental results (PSP and pressure taps) agreed very well (see Fig. 11). It is important to say that, basically, the PSP technique responds better to higher pressure gradients, and this normally occur for high Mach numbers.

A more careful analysis of Fig. 10 shows how well the PSP technique could determine the shock location, indicated by the abrupt change of color from cyan to green at $43 \%$ of the chord and the figure shows that in all span region no notable threedimensional effects could be observed. The dark blue region located around $25 \%$ of the chord should continue until the shock location at $43 \%$. However before the shock occurrence the pressure had an increase denounced by changing the color from the dark blue to the cyan. It is important to observe that this color change showed some oscillation in the span direction indicating instabilities. This region that was so noticeable in the PSP image is the region of interaction between laminar boundary layer and the incident shock wave.

Anyway, one value from the literature can be used for comparison. Just after the shock wave passage the pressure coefficient from the literature was used to calculate the pressure at this location considering the stagnation pressure of $94000 \mathrm{~Pa}$, which resulted in $53000 \mathrm{~Pa}$, fairly agreeing with the PSP and pressure taps results.

In Figure 12 one can observe the comparisons between PSP and pressure taps results obtained with the conditions of Test $B$. In these study cases the Mach numbers were 0.6 , the camera aperture was the same but the stagnation temperatures were very different - total temperature of $33.1 \mathrm{C}$ and $42.2 \mathrm{C}$ corresponding to static temperature of $27 \mathrm{C}$ and $38 \mathrm{C}$, respectively. As expected, the temperature variation yields a disagreement in the PSP results but the total pressure variation observed for a $9 \mathrm{C}$ variation was about $1300 \mathrm{~Pa}$. This is expected since the luminescence of the PSP paint can also be quenched by the temperature, although the pre-calibration procedure applied. 


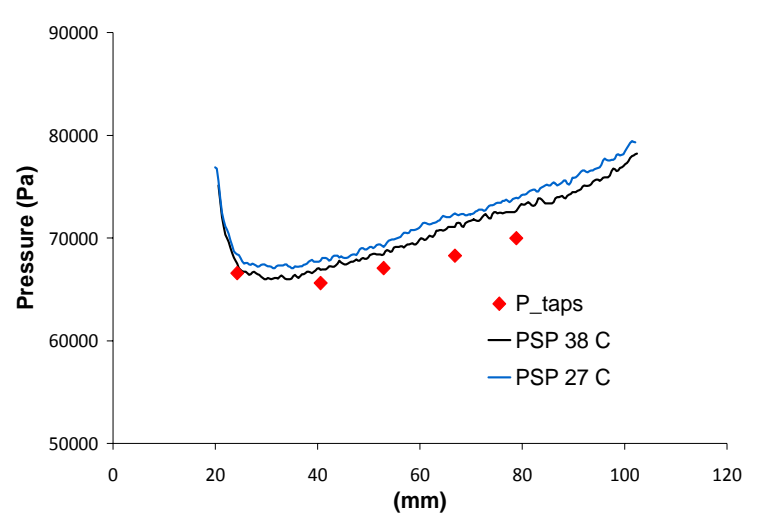

Figure 12. Pressure profiles obtained by varying the position of the illumination source.

Figure 13 describes the results from Test C including one configuration from Test $\mathrm{A}$ at the same Mach number: the impact due to the camera aperture. In this case the pressure taps values were obtained calculating the average value from the related tests. As expected that with the aperture of 11 , the quality of image was reduced and the results obtained in this case was not only the worst but also the noisiest, as can be observed from the pressure profiles presented in Fig. 13. On the other hand, for camera aperture of 2.8 the pressure results present a smaller level of noisy. From the figure one can depict that the best agreement with the pressure taps values can be found with camera aperture between 2.8 and 5.6. Comparing these results with those of other effects (Mach number and temperature) it is possible to conclude that the most significant parameter to adjust in the PSP technique is the camera aperture: from 2.8 to 11 of aperture resulted in a total variation of about $6000 \mathrm{~Pa}$.



Figure 13. Pressure profiles obtained by varying the camera aperture for Mach number 0.6.

Besides these tests another one is very important. The illumination also plays a role in the accuracy of the PSP results since this is a factor that affects the quality of the images. Figure 14 shows the effect of the illumination source when it is approached, and a significant noisy was introduced in the pressure measurements. It is worth note that the shape of the curves had only small difference (about $900 \mathrm{~Pa}$ ) and they agreed well with pressure taps results.

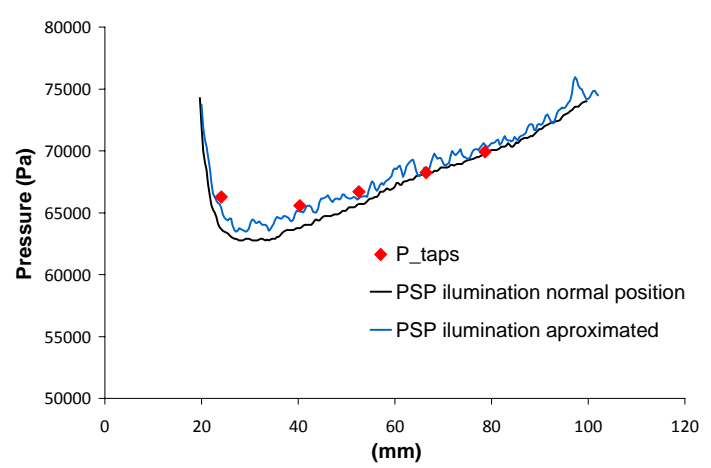

Figure 14. Pressure profiles obtained by varying the position of the illumination source.

\section{CONCLUSIONS}

Very important results concerning the implementation of the PSP technique in TTP were obtained related with the effects caused by variations of key parameters: Mach number, stagnation temperature, camera aperture and light source proximity. The Mach number variation effects indicated that a better result is obtained for higher speed regimes. For Mach number 0.8 the values fairly agree with the literature, not including the region where it has occurred interaction between the laminar boundary layer and the shock wave. The discrepancies caused by the key parameters were, in terms of pressure variation: $1300 \mathrm{~Pa}$ for $9 \mathrm{C}$ of the stagnation temperature; $900 \mathrm{~Pa}$ for distance of the light source; $6000 \mathrm{~Pa}$ for camera aperture from 2.8 to 11. This fact indicates that a special concern must be given for determining the best camera aperture positioning.

\section{ACKNOWLEDGEMENTS}

The three authors thanks CNPq for the financial support through the process 310646/2012-0 and the second authors thanks CNPq also through the process 560200/2010-2 (first and second author).

\section{REFERENCES}

Basu, B. J., Vasantharajan, N., and Raju, C., 2009, A Novel Pyrene-based Binary Pressure Sensitive Paint with low Temperature Coefficient and Improved Stability, Sensors and Actuators B: Chemical, Vol. 138, pp. 283-288.

Bell, J. H., Schairer, E. T., Hand, L. A., and Mehta, R. D., 2001, Surface Pressure Measurements Using Luminescent Coatings, Annual Review of Fluid Mechanics, Vol.33, pp. 155-206.

Engler, R. H., Klein, C., and Trinks, O., 2000, Pressure Sensitive Paint Systems for Pressure Distribution Measurements in wind Tunnels and Turbomachines, Measurement Science and 
Technology, Vol. 11, pp. 1077-1085.

Falcão Filho, J. B. P., Avelar, A. C., and Reis, M. L. C. C., 2009, Historical Review and Future Perspectives for the PTT - IAE Pilot Transonic Wind Tunnel, Journal of Aerospace and Technology and Management, ISSN 1984-9648,Vol. 1, No. 1, Jan-Jun 2009

Gregory, J. W., Asai, K., Kameda, M. T., Liu, T., and Sullivan, J. P., 2007, A Review of Pressuresensitive Paint for High-speed and Unsteady Aerodynamics, Department of Aerospace Engineering, The Ohio State University, Ohio, USA.

Harris, C. D., 1981, Two-dimensional Aerodynamic Characteristics of the NACA 0012 Airfoil in the Langley 8-foot Transonic Pressure Tunnel, NASA TM 81927.

Liu, T., Sullivan, J. P., 2005, Pressure and Temperature Sensitive paints, Springer Berlin.

Kurita, M., Nakakita, K., Mitsuo, K., and Watanabe, S., 2006, Temperature Correction of Pressure-Sensitive Paint for Industrial Wind Tunnel Testing, Journal of Aircraft, Vol. 43, No. 5, September-October 2006, DOI: 10.2514/1.13608.

Van Dyke, M., 1988, An Album of Fluid Motion, 4th Edition, The Parabolic Press, Department of Mechanical Engineering, Stanford University, Stanford, California.

Vardaki, E., Stokes, N. P., Fonov, S. D., and Crafton, J. W., 2010, Pressure Sensitive Paint Measurements at the ARA Transonic Wind Tunnel, in: 27th AIAA Aerodynamic Measurement Technology and Ground Testing Conference, Chicago, Illinois, AIAA 2010-4796. 